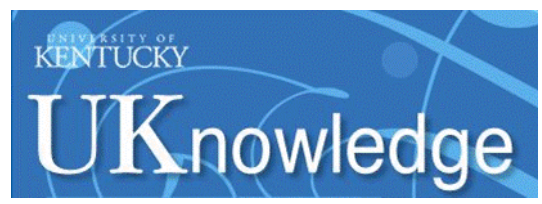

University of Kentucky

UKnowledge

CRVAW Faculty Journal Articles

Center for Research on Violence Against

Women

$7-2003$

\title{
Psychosocial Stress and Cervical Neoplasia Risk
}

Ann L. Coker

University of Texas Health Science Center at Houston, ann.coker@uky.edu

Sharon M. Bond

Medical University of South Carolina, bondsm@musc.edu

Margaret M. Madeleine

University of Washington - Seattle Campus, mmadelei@fhcrc.org

Kathryn J. Luchok

University of South Carolina, luchok@mailbox.sc.edu

Lucia Pirisi

University of South Carolina, pirisi@uscmed.sc.edu

Follow this and additional works at: https://uknowledge.uky.edu/crvaw_facpub

Part of the Mental and Social Health Commons, Obstetrics and Gynecology Commons, Psychiatry and Psychology Commons, Psychology Commons, and the Public Health Commons

Right click to open a feedback form in a new tab to let us know how this document benefits you.

\section{Repository Citation}

Coker, Ann L.; Bond, Sharon M.; Madeleine, Margaret M.; Luchok, Kathryn J.; and Pirisi, Lucia,

"Psychosocial Stress and Cervical Neoplasia Risk" (2003). CRVAW Faculty Journal Articles. 136.

https://uknowledge.uky.edu/crvaw_facpub/136

This Article is brought to you for free and open access by the Center for Research on Violence Against Women at UKnowledge. It has been accepted for inclusion in CRVAW Faculty Journal Articles by an authorized administrator of UKnowledge. For more information, please contact UKnowledge@lsv.uky.edu. 


\section{Psychosocial Stress and Cervical Neoplasia Risk}

\section{Digital Object Identifier (DOI)}

http://dx.doi.org/10.1097/01.PSY.0000041471.57895.08

\section{Notes/Citation Information}

Published in Psychosomatic Medicine, v. 65, no. 4, p. 644-651.

This manuscript provided with permission from the publisher, and also accessible through the journal's website at http://www.psychosomaticmedicine.org/content/65/4/644.full.pdf+html.

Dr. Ann Coker had not been a faculty member of the University of Kentucky at the time of publication. 


\title{
Psychosocial Stress and Cervical Neoplasia Risk
}

\author{
Ann L. Coker, PhD, Sharon Bond, CNM, MSn, Margaret M. Madeleine, PhD,
}

Kathryn Luchok, PhD, and Lucia Pirisi, MD

\begin{abstract}
Objective: We assessed the association between psychosocial stress and preinvasive cervical neoplasia development controlling for HR-HPV infection. Methods: This case-control study enrolled low-income women receiving family planning services at health department clinics. There were 59 cases with biopsy confirmed HSIL and 163 with low-grade SIL and 160 controls with normal cervical cytology. A modified SLE scale was used to measure stressful events and the perceived impact of the event in the prior 5 years. Unconditional logistic regression was used to assess SIL risk and stressful events scores and by subscales. Results: After adjusting for age, HR-HPV infection, and lifetime number of sex partners, the SLE count score was associated with an increased risk of SIL among white women $(\mathrm{aOR}=1.20 ; 95 \% \mathrm{CI}=1.04,1.38)$ yet not among African American women $(\mathrm{aOR}=1.02 ; 95 \%$ $\mathrm{CI}=0.87,1.19$ ). The relationship stress subscale (divorce, infidelity, an increase in the number of arguments, and psychological and physical partner violence) was the only one of four subscales (loss, violence, and financial stress) associated with SIL, again, only among white women $(\mathrm{aOR}=1.54 ; 95 \% \mathrm{CI}=1.21,1.96)$. Conclusions: These data suggest that psychosocial stress may play a role in SIL development. Future studies are needed to confirm these findings, to explore racial difference in reporting stress, and to explore the mechanism through which psychosocial stress may affect cervical neoplasia risk. Key words: cervical neoplasms, psychological stress, human papillomavirus, women, ethnicity, epidemiology.
\end{abstract}

$\mathbf{a O R}=$ adjusted odds ratio; ASCUS $=$ atypical squamous cells of undetermined significance; HC = hybrid capture; HIV = human immunodeficiency virus; HR-HPV = high-risk human papillomavirus; HSIL = high grade squamous intraepithelial lesions; $\mathbf{I C C}=$ invasive cervical cancer; $\mathbf{L S I L}=$ low-grade squamous intraepithelial lesions; SLE = stressful life events; STI = sexually transmitted infection; $\mathbf{9 5} \% \mathbf{C I}=95 \%$ confidence interval.

\section{INTRODUCTION}

$\mathrm{H}$ R-HPV are etiologically linked to cervical neoplasia (13). Although HR-HPV infection is a necessary cause of cervical neoplasia, it is not sufficient. A small percentage of HR-HPV positive women develop HSIL or cancer. HPV infection is usually transient, but persistence of the virus is linked to HSIL and cancer (4). Persistence is a function of the host immune response as indicated by its association with a suppressed lymphoproliferative response to infection (5). Stress could affect risk of SIL by increasing risk of HR-HPV persistence.

Previous research shows that psychosocial stress, negative coping styles, and limited social support are associated with a variety of health problems (6-9), including susceptibility to viral agents. Cohen et al. (10-13) have shown that psychosocial stress and limited social support $(14,15)$ affect susceptibility to the common cold. Relatively few epidemiologic studies, however, have investigated the effects of psychological stress, coping skills, and social support on cervical neoplasia risk (16-20). There is evidence that stress may affect cervical neoplasia risk by decreasing a woman's immunocompetence (17).

Several studies have explored the links between HPV-

From Department of Epidemiology (A.L.C.), University of Texas School of Public Health, Houston, Texas; School of Nursing (S.B.), Medical University of South Carolina, Charleston, South Carolina; Program in Epidemiology (M.M.M.), Fred Hutchinson Cancer Center, Seattle, Washington; Department of Health Promotion, Education, Behavior (K.L.), Norman J. Arnold School of Public Health; and Department of Pathology (L.P.), School of Medicine, University of South Carolina, Columbia, South Carolina

Address reprint requests to: Ann L. Coker, PhD, University of Texas School of Public Health 1200 Herman Pressler Dr., Rm. E-1009, PO Box 20186, Houston, TX 77225. Email: acoker@sph.uth.tmc.edu

Received for publication May 2, 2001; revision received August 22, 2002.

DOI: 10.1097/01.PSY.0000041471.57895.08 related infections and immune suppression, coping skills, and stress. Immunocompromised subjects, including renal allograft (21) and HIV-infected patients (22), are more likely to develop a range of infections (23), including genital warts (24, 25). Psychosocial stress may also be linked to immunosuppression among another immunosuppressed population, such as those with HIV infections. In a small study of $36 \mathrm{HIV}+$ women, Byrnes et al. (20) found that pessimism was associated with lower natural killer cell counts and cytotoxic suppressor cells after controlling for HR-HPV +, behavioral factors, and stressful life events. These findings suggest that a pessimistic attitude or negative response to life stress may negatively affect immune function, HR-HPV persistence, and perhaps subsequent cervical lesion development and progression. Higher cortisol levels, indicating higher stress, were associated with cervical neoplasia in a small Italian casecontrol study (26). Antoni and Goodkin (19) found that women with negative coping styles were more likely to have HSIL than were women with more positive coping skills. Goodkin et al. (18) reported that uncontrollable life stressors were significantly associated with higher levels of SIL. Sexual abuse during childhood (27) or by an intimate male partner (28), which are both stressful events, have been linked to cervical neoplasia.

Although these findings are intriguing, each study has specific methodological problems that make interpretation of results difficult. The majority of the studies are quite small $(<100$ subjects), which limits the estimates of effects and generalizability. Most do not address HR-HPV positivity, the primary etiologic agent for high-grade cervical neoplasia. The measures of psychosocial stress also differ markedly across studies, which makes comparisons difficult. Ascertaining measures of stress in a case-control setting after disease detection may also be problematic since some reported stress may be in response to knowledge of disease detection. To better understand this process, researchers need to include biological measures of chronic stress and humoral immune response to HPV infection linked to cervical cancer.

The purpose of the current study is to investigate the association between SLE as a measure of psychosocial stress 
and risk of cervical neoplasia using data from women with low- and high-grade cervical lesions. We hypothesize that women with higher stressful life events scores will be more likely to have cervical neoplasia.

\section{METHODS \\ Subjects}

This is an analysis of baseline data from the Cervical Cancer Education and Prevention Project, undertaken in a three county area of the South Carolina Department of Health and Environmental Control Family Planning clinics near Charleston and Columbia, South Carolina. The purpose of this project was to provide care for low-income women with low-grade cervical lesions and to assess the relationship between stress and SIL. All women included in this study were referred from their family planning clinic by nurses and had LSIL or ASCUS on two consecutive Pap smears between April 1996 and September 1999. Study participation included careful evaluation of the woman's cervix in visits every 4 to 6 months over two years with the use of Pap smears, cervicography, colposcopy with cervical biopsy, if indicated, and an assessment for STI (eg, bacterial vaginosis, chlamydia, and gonorrhea). An additional cervical sample was taken for HPV testing. A trained interviewer conducted a computer-assisted personal interview with all consenting women. This interview, which included the stressful life events questions, was completed at baseline before women knew their cytology or pathology results. Medical care was provided at no cost to study participants. Women received a $\$ 10$ incentive payment for study participation. The University of South Carolina Institutional Review Board approved the study.

\section{Study Design}

To address the question of psychosocial stress and cervical neoplasia, we conducted a case-control analysis with the baseline questionnaire data, the cervical cytology, and the cervical sample for HPV typing. Cases are women with HSIL or LSIL on the Pap smear collected on entry into this study and confirmed by a follow-up biopsy. Controls were women whose Pap smear was normal at study entry. All women had some cervical abnormality that led to study inclusion; however, when the baseline Pap smears were taken, often 6 to 9 months after the original Pap smear that lead to study referral, and evaluated by another laboratory used as our reference laboratory (MUSC), many women had normal cervical cytology. These women made up our control group. The same laboratory (MUSC) evaluated all cervical cytology and pathology samples in a blinded fashion thus increasing the reliability of the testing

A total of 635 women were referred into the Cervical Cancer Education and Prevention Project; 94.3\% (601) agreed to participate. Of the 601 women enrolled, 546 (90.8\%) completed baseline interviews and 593 provided cervical samples that were of sufficient quality for HR-HPV typing $(98.7 \%$ $\beta$-globin positive). Of the 538 women who were interviewed and had sufficient cervical DNA for HPV typing, 60 women had biopsy confirmed HSIL, 180 had LSIL, and 174 had normal cervical cytology. The remaining 124 women had ASCUS on biopsy or Pap smears and were excluded from this analysis. We also excluded women with a history of treatment for cervical neoplasia (2 LSIL cases and 1 control) and those who did not provide complete data on the SLE measures or other demographic data (1 HSIL, 15 LSIL, and 13 controls). Our final sample size for analysis was 59 HSIL cases, 163 LSIL cases, and 160 controls. We limit disease misclassification by including biopsy confirmed SIL cases, and we have required controls to have more than one recent normal Pap smear or a normal cervical biopsy.

\section{Questionnaire}

After informed consent, subjects were interviewed to obtain information about behavioral factors associated with increased risk of cervical neoplasia. These factors included demographic characteristics (ie, age, race, education, occupation), sexual and reproductive history, cigarette smoking and alcohol use, physical activity, sexually transmitted infection history (including treatment for abnormal Pap smears and reasons for treatment delay, if appropriate), and history of stressful life events. We also asked women whether they were satisfied in their relationships with their relatives/family, friends, and with their current male partner; five-item response options ranged from very satisfied to very dissatisfied. We created three separate dichotomous variables to measure relationship dissatisfaction with friends, relatives, and the current male partner.

\section{Cervical Sample Collection and HR-HPV Analyses}

HPV DNA cervical specimens were obtained by inserting a cytobrush into the endocervical canal and placing the sample in a transport media supplied by Digene. Samples were frozen and later transported to the University of South Carolina, Department of Pathology, for interpretation. DNA was extracted from cervical smear samples using standard procedures and amplification for $\beta$-globin DNA sequences was conducted to indicate whether sufficient cervical DNA was present in the sample $(2 \% \beta$-globin were negative). A unique study number was assigned to each cervical sample. HPV lab technicians were blinded to the case or control status of subjects to minimize differential misclassification. HPV positivity was determined using Hybrid Capture I techniques according to the manufacture's guidelines; the same individual conducted HPV typing for all samples. We assessed high-risk (HPV 16, 18, 31, 33, 35, 45, 51, 52 and 56) and low-risk types (HPV 6, 11, $42,43,44)$. A dichotomous variable for HR-HPV positivity (positive compared with negative) was used in the analysis.

\section{SLE Measurement}

We based our measure of SLE on the work of Norbeck $(29,30)$. Norbeck and Anderson (31) have used this instrument to measure life stress among African American, Hispanic, and white women, and to correlate life stress with pregnancy outcomes. Our adapted measure includes 17 events that are more likely to occur among lower income and younger women. All events are negative; examples of these events include infidelity, arrest, partner violence, sexual assault, becoming homeless, and moving back in with parents. We asked women whether they had ever experienced the event and, if so, their age when they first experienced the event (latency), how upset they were when the event first occurred (high impact), and their age when they last experienced the event (recency). The stressful life event SLE count score is the sum of the number of events reported to have occurred $<5$ years before the interview; the maximum score is 17 with a range between 0 and 12. The high impact SLE count score is the sum of the number of stressful life events occurring within the past 5 years for which the woman reported being very upset by the event; again the maximum value for the high impact SLE score was 17 with a range of $0-9$. An event was counted only once even if the event had happened more than once in the past 5 years.

We used exploratory principal component factor analysis and identified four subscales of stressful events with factor structure correlations of $>45$. The first is loss, including death of a parent (correlation with factor $1=45$ ), close friend (correlation $=52$ ), or close family member $($ correlation $=45)$. Second, relationship stressors ( 5 items), including emotional abuse by partner (correlation with factor $2=74$ ), physical abuse by partner (correlation $=67$ ), divorce (correlation $=61$ ), infidelity $($ correlation $=58)$, and increased number of arguments (correlation $=55$ ). Third, five financial stressors, including the woman or her partner being fired from a job (correlation with factor $3=47$ ), the woman being arrested (correlation $=50$ ), or having to move back in with parents (correlation $=49$ ), the woman being homeless (correlation $=49)$. Finally, violence stressors $(4$ items): woman being robbed (correlation with factor $4=74$ ), sexually assaulted (correlation $=70$ ), physically assaulted by someone other than her partner (correlation $=68$ ), or her partner being arrested (correlation $=45$ ). We created both SLE count scores (count of events occurring in the past 5 years) and high impact SLE count (count of events occurring in the past 5 years that were very upsetting to women) scores for each of the four subscales.

\section{Statistical Analysis}

We used logistic regression (32) to estimate the risk of cervical neoplasia (HSIL and LSIL combined) associated with stressful life events controlling for HR-HPV in this case-control study. All analyses were conducted in Statistical Analysis Software (33). The stressful life events measures were 
included in separate logistic regression models as the SLE count score, the high impact SLE count score, and the four subscales. Race and HR-HPV positivity were assessed as effect modifiers using stratified analysis. The Breslow-Day test for homogeneity of the relative risk estimates were calculated for these two effect modifiers of the SLE and cervical neoplasia association assuming a multiplicative interaction. The distribution of the SLE scores and subscales are presented in Table 1 by African American or white race. Logistic and linear regressions were used to test for differences in the proportion and means of the SLE scores by race.

Confounding was assessed by determining factors associated with SIL (Table 2) and with a dichomotomized SLE count scores at the highest quintile of the SLE count score (Table 3). The following confounders were assessed as continuous variables: age, number of household members, duration of cigarette smoking in years, age at first sexual intercourse, and number of male sex partners. The remaining confounders were included as dichotomous variables: education ( $\leq 12$ years vs. $13+$ years), HR-HPV positivity (positive vs. negative), ever vs. never self-reported history of a sexually transmitted infection (including genital herpes, chlamydia, gonorrhea, syphilis, HIV, or pelvic inflammatory disease), ever vs. never had genital warts, current smoking status (current cigarette smoker vs. former and never smokers), and relationship dissatisfaction with relatives, friends, or current male partner (dissatisfied vs. satisfied).

The adjusted association between SIL case and control status and the SLE measures are presented in Table 4. Separate logistic regression model were run adjusting for confounders (age, HR-HPV positivity, and lifetime number of sex partners) within the two race status for each SLE measure.

\section{RESULTS}

Subjects included in this study were young (mean age 24.5 $\pm \mathrm{SD} 6.5$ ), 37.7\% had some education beyond high school, the majority $(61.3 \%)$ were single, $44.5 \%$ were white, and 55.5\% were African American.

The relative risk of SIL associated with SLE scores was significantly different between white and African American women; the Breslow-Day $\chi^{2}$ tests for homogeneity was 4.40 $(p=.03)$; therefore, subsequent analyses were stratified by race. Table 1 provides the frequency and distribution of SLE count scores and specific stressful life events items by race. When compared with African American women, white women had higher SLE count and higher high impact SLE count scores $(p<.001)$ and were more likely to report specific SLE events (see Table 1). White women had significantly higher SLE count scores for the relationship and financial stress subscales compared with African American women.

HR-HPV positivity did not modify the association between high SLE count scores and SIL risk; the Breslow-Day $\chi^{2}$ test for homogeneity was $1.06(p=.34)$.

Table 2 presents potential confounders associated with SIL. Younger women and women with an earlier age at first having sexual intercourse were more likely to be have had SIL. As expected, HR-HPV positivity was the strongest risk factor for SIL (Table 2). No other demographic, sexual, or reproductive risk factors were associated with SIL case status.

Table 3 presents correlates of higher SLE count scores defined as the highest quintile of the SLE count score (dichot-

TABLE 1. Distribution of SLE Scores and Subscale by Race

\begin{tabular}{|c|c|c|}
\hline & $\begin{array}{l}\text { White Women } \\
\qquad(N=170)\end{array}$ & $\begin{array}{l}\text { African American Women } \\
\qquad(N=212)\end{array}$ \\
\hline \multicolumn{3}{|l|}{ Total scores } \\
\hline SLE count score (range $0-12)^{a}$ & $3.88 \pm 2.50^{* *}$ & $3.04 \pm 2.06$ \\
\hline High Impact SLE count score (range $0-12)^{a}$ & $2.43 \pm 2.10^{* *}$ & $1.78 \pm 1.74$ \\
\hline \multicolumn{3}{|l|}{ Subscales (and specific items with the subscales) } \\
\hline Loss (range $0-3)^{a}$ & $0.66 \pm 0.72$ & $0.76 \pm 0.74$ \\
\hline Death of a close family member & $32.4 \%$ & $41.6 \%$ \\
\hline Friend & $28.2 \%$ & $24.8 \%$ \\
\hline Parent & $5.3 \%$ & $9.4 \%$ \\
\hline Relationship stress (range $0-5)^{a}$ & $1.76 \pm 1.48^{\star *}$ & $1.34 \pm 1.25$ \\
\hline Divorced & $25.9 \% * *$ & $9.3 \%$ \\
\hline Infidelity & $45.9 \%$ & $53.7 \%$ \\
\hline Increase in arguments & $45.3 \%$ & $37.7 \%$ \\
\hline Severe physical abuse by a partner (beaten up) & $20.6 \%$ & $14.4 \%$ \\
\hline Emotionally abused by intimate partner & $38.8 \% * *$ & $18.2 \%$ \\
\hline Financial stress (range $0-5)^{a}$ & $0.98 \pm 0.99^{\star *}$ & $0.56 \pm 0.77$ \\
\hline Woman fired from job & $18.8 \%$ & $12.6 \%$ \\
\hline Partner fired from job & $17.7 \% *$ & $8.8 \%$ \\
\hline Woman arrested & $19.4 \% * *$ & $7.5 \%$ \\
\hline Homeless & $9.4 \%$ ** & $2.3 \%$ \\
\hline Woman moved back in with parent(s) & $32.4 \%$ * & $22.5 \%$ \\
\hline Violence stress (range $0-4)^{a}$ & $0.49 \pm 0.73$ & $0.38 \pm 0.61$ \\
\hline Forced sex & $2.9 \%$ & $2.9 \%$ \\
\hline Partner arrested & $25.9 \% *$ & $17.0 \%$ \\
\hline Woman robbed & $16.5 \%$ & $13.6 \%$ \\
\hline Woman assaulted by someone other than her partner & $4.1 \%$ & $3.7 \%$ \\
\hline
\end{tabular}

\footnotetext{
${ }^{\mathrm{a}}$ Means $\pm \mathrm{SD}$.

$* p=0.01-0.05$.

$* * p<0.01$.
} 
TABLE 2. Demographic, Behavioral, and Sexual Risk Factors for Cervical SIL

\begin{tabular}{|c|c|c|c|}
\hline & $\begin{array}{c}\text { SIL Cases } \\
(N=222)\end{array}$ & $\begin{array}{l}\text { Normal Controls } \\
\quad(N=160)\end{array}$ & $\begin{array}{c}\text { Unadjusted Odds Ratio } \\
(\& 95 \% \mathrm{Cl}) \\
\text { SIL vs Normal }\end{array}$ \\
\hline $\mathrm{Age}^{\mathrm{a}}$ & $23.5 \pm 5.7$ & $26.0 \pm 7.3$ & $0.94(0.91,0.97)^{*}$ \\
\hline Race: white, \% & $45.7 \%$ & $42.2 \%$ & $1.15(0.77,1.74)$ \\
\hline Education: $\leq$ high school, \% & $63.7 \%$ & $60.9 \%$ & $1.13(0.74,1.71)$ \\
\hline Number of household members ${ }^{a}$ & $3.6 \pm 1.6$ & $3.5 \pm 1.7$ & $1.03(0.91,1.18)$ \\
\hline HR-HPV positive, $\%$ & $60.1 \%$ & $16.2 \%$ & $7.64(4.64,12.59)^{\star *}$ \\
\hline Ever had a STI, \% & $48.9 \%$ & $41.6 \%$ & $1.34(0.89,2.02)$ \\
\hline Ever had genital warts, \% & $8.5 \%$ & $5.6 \%$ & $1.57(0.69,3.57)$ \\
\hline Current smoker, \% & $32.7 \%$ & $24.8 \%$ & $1.47(0.94,2.32)$ \\
\hline Years of cigarette smoking ${ }^{a}$ & $3.0 \pm 4.9$ & $2.9 \pm 5.5$ & $1.01(0.97,1.05)$ \\
\hline Age at first sex ${ }^{a}$ & $15.6 \pm 2.3$ & $16.2 \pm 2.5$ & $0.89(0.81,0.97)^{*}$ \\
\hline Lifetime number of sex partners ${ }^{a}$ & $6.8 \pm 6.5$ & $6.3 \pm 6.2$ & $1.01(0.98,1.05)$ \\
\hline
\end{tabular}

${ }^{\mathrm{a}}$ Means $\pm \mathrm{SD}$.

$* p=0.01-0.05$.

$* * p<0.01$.

TABLE 3. Risk of Higher SLE Count Score Associated with Demographic Factors, Sexual Risk Factors, Negative Health Behaviors, and Relationship Dissatisfaction

\begin{tabular}{|c|c|c|c|}
\hline & $\begin{array}{l}\text { Highest Quintile } \\
\text { of SLE Count } \\
\text { Score }(N=73)\end{array}$ & $\begin{array}{l}\text { Lower Quintiles } \\
\text { of SLE Count } \\
\text { Score } \\
(N=309)\end{array}$ & $\begin{array}{l}\text { Unadjusted OR } \\
(\& 95 \% \mathrm{Cl})\end{array}$ \\
\hline \multicolumn{4}{|l|}{ Demographic Factors } \\
\hline $\mathrm{Age}^{\mathrm{a}}$ & $24.4 \pm 6.1$ & $24.5 \pm 6.6$ & $0.99(0.96,1.04)$ \\
\hline Education: $\leq 12, \%$ & $65.8 \%$ & $61.5 \%$ & $1.18(0.69,2.01)$ \\
\hline Race: white, \% & $60.3 \%$ & $40.8 \%$ & $2.78(1.35,3.86)^{*}$ \\
\hline Number of Household members ${ }^{a}$ & $3.3 \pm 1.6$ & $3.6 \pm 1.6$ & $0.86(0.73,1.01)$ \\
\hline \multicolumn{4}{|l|}{ Sexual risk factors } \\
\hline Ever had a STI, \% & $57.5 \%$ & $43.0 \%$ & $1.75(1.04,2.94)^{*}$ \\
\hline Ever had genital warts, \% & $13.7 \%$ & $5.8 \%$ & $2.83(1.00,5.38)^{*}$ \\
\hline Age at first sexual intercourse ${ }^{a}$ & $15.6 \pm 3.0$ & $15.9 \pm 2.3$ & $0.94(0.83,1.04)$ \\
\hline Number of lifetime male sex partners ${ }^{a}$ & $7.7 \pm 6.0$ & $6.3 \pm 6.4$ & $1.03(0.99,1.07)$ \\
\hline HR-HPV positivity ${ }^{\mathrm{b}}$ & $43.1 \%$ & $35.6 \%$ & $1.81(1.00,3.28)^{*}$ \\
\hline \multicolumn{4}{|l|}{ Negative health behaviors } \\
\hline Average hours per 24 spent sleeping ${ }^{a}$ & $7.4 \pm 2.1$ & $7.5 \pm 1.9$ & $0.97(0.84,1.11)$ \\
\hline Average hours of little physical activity ${ }^{a}$ & $4.6 \pm 2.7$ & $4.7 \pm 2.7$ & $0.99(0.90,1.09)$ \\
\hline$>20$ alcoholic drinks per month (\%) & $5.5 \%$ & $7.5 \%$ & $0.73(0.25,2.19)$ \\
\hline Current smoker (\%) & $45.2 \%$ & $25.9 \%$ & $2.42(1.43,4.11)^{\star *}$ \\
\hline Years of cigarette smoking ${ }^{a}$ & $3.5 \pm 4.6$ & $2.8 \pm 5.3$ & $1.04(0.98,1.07)$ \\
\hline \multicolumn{4}{|l|}{$\%$ Dissatisfied in relationship with } \\
\hline Relatives & $11.0 \%$ & $4.9 \%$ & $2.47(1.01,6.08)^{\star}$ \\
\hline Friends & $20.6 \%$ & $11.7 \%$ & $1.85(0.94,3.65)$ \\
\hline Current male partner $(N=321)^{c}$ & $17.8 \%$ & $4.9 \%$ & $4.36(1.97,9.66)^{* *}$ \\
\hline
\end{tabular}

$* p=0.01-0.05 . * * p<0.01$

${ }^{\mathrm{a}}$ Means $\pm \mathrm{SD}$.

${ }^{\mathrm{b}}$ Odds ratio (OR) adjusted for SIL because HR-HPV is so strongly associated with SIL.

${ }^{\mathrm{c}}$ Among those with current partners.

STI, eg, chlamydia, gonorrhea, syphilis, HIV, or pelvic inflammatory disease.

omous dependent variable for logistic regression analysis). Race was the only demographic factor associated with having a higher SLE count score (crude OR $=2.78 ; 95 \% \mathrm{CI}=1.35$, 3.86). Ever having had a sexually transmitted infection and specifically genital warts were associated with higher SLE count scores. Furthermore, HR-HPV positivity was associated with an increased risk of having a higher SLE count score.
Among variables characterizing negative health behaviors, current cigarette smoking was the only behavior associated with a higher SLE count score. Dissatisfaction with friends and with a current partner was significantly associated with higher SLE count scores.

In Table 4, we present the analysis of the association between SIL and stressful life event scores (eg, count of 
TABLE 4. Stressful Life Events and Cervical SIL Among African American and White Women

\begin{tabular}{|c|c|c|c|c|c|c|}
\hline \multirow{2}{*}{ Stressful Life Event } & \multicolumn{3}{|c|}{ Whites, 101 SIL/68 normals } & \multicolumn{3}{|c|}{ African-Americans, 119 SIL/90 normals } \\
\hline & $\begin{array}{l}\text { Prevalence of stress, } \\
\text { Mean } \pm S D\end{array}$ & \multicolumn{2}{|c|}{$\mathrm{OR}^{\mathrm{a}}, \& 95 \% \mathrm{Cl}$} & \multicolumn{2}{|c|}{$\begin{array}{l}\text { Prevalence of stress, } \\
\text { Mean } \pm S D\end{array}$} & $\mathrm{OR}^{\mathrm{a}}, \& 95 \% \mathrm{Cl}$ \\
\hline $\begin{array}{l}\text { SLE count score }{ }^{\mathrm{b}} \\
\text { (range } 0-12 ; 17 \text { possible) }\end{array}$ & $3.88 \pm 2.50^{* *}$ & \multicolumn{2}{|c|}{$1.20(1.04,1.38)$} & \multicolumn{2}{|c|}{$3.04 \pm 2.06$} & $1.02(0.87,1.19)$ \\
\hline $\begin{array}{l}\text { High impact SLE score } \\
\quad \text { (range } 0-9 ; 17 \text { possible) }\end{array}$ & $2.43 \pm 2.10^{\star *}$ & \multirow{2}{*}{\multicolumn{2}{|c|}{$1.30(1.10,1.55)$}} & \multirow{2}{*}{\multicolumn{2}{|c|}{$1.78 \pm 1.74$}} & $1.02(0.84,1.23)$ \\
\hline Subscales & & & & & & \\
\hline \multicolumn{7}{|l|}{ Loss $^{\mathrm{a}}$ (range $0-3$ ) } \\
\hline Count within subscale ${ }^{b}$ & $0.66 \pm 0.72$ & \multirow{2}{*}{\multicolumn{2}{|c|}{$\begin{array}{l}1.02(0.64,1.63) \\
1.14(0.65,1.99)\end{array}$}} & \multicolumn{2}{|c|}{$0.76 \pm 0.74$} & $0.96(0.62,1.48)$ \\
\hline High impact within subscale $e^{c}$ & $0.44 \pm 0.62$ & & & \multicolumn{2}{|c|}{$0.53 \pm 0.70$} & $0.81(0.51,1.28)$ \\
\hline \multicolumn{7}{|l|}{ Relationship ${ }^{\mathrm{b}}$ (range $0-5$ ) } \\
\hline Count within subscale ${ }^{b}$ & $1.76 \pm 1.48^{* *}$ & \multicolumn{2}{|c|}{$1.54(1.21,1.96)$} & \multicolumn{2}{|c|}{$1.34 \pm 1.25$} & $1.03(0.79,1.33)$ \\
\hline High impact within subscale $e^{c}$ & $1.26 \pm 1.36^{\star *}$ & \multicolumn{2}{|c|}{$1.69(1.28,2.22)$} & \multicolumn{2}{|c|}{$0.82 \pm 1.06$} & $1.03(0.76,1.42)$ \\
\hline \multicolumn{7}{|l|}{ Financial ${ }^{\mathrm{C}}$ (range $0-5$ ) } \\
\hline Count within subscale ${ }^{b}$ & $0.98 \pm 0.99$ & \multicolumn{2}{|c|}{$1.18(0.84,1.67)$} & \multicolumn{2}{|c|}{$0.56 \pm 0.77$} & $1.06(0.69,1.63)$ \\
\hline High impact within subscale $e^{c}$ & $0.47 \pm 0.72$ & \multicolumn{2}{|c|}{$1.46(0.91,2.32)$} & \multicolumn{2}{|c|}{$0.22 \pm 0.51$} & $1.54(0.79,3.00)$ \\
\hline \multicolumn{7}{|l|}{ Violence/legal ${ }^{\mathrm{d}}$ (range $0-4$ ) } \\
\hline Count within subscale ${ }^{\mathrm{b}}$ & $0.49 \pm 0.73$ & \multicolumn{2}{|c|}{$1.05(0.66,1.65)$} & \multicolumn{2}{|c|}{$0.38 \pm 0.61$} & $1.06(0.63,1.78)$ \\
\hline High impact within subscale ${ }^{c}$ & $0.27 \pm 0.58$ & \multicolumn{2}{|c|}{$0.91(0.52,1.60)$} & \multicolumn{2}{|c|}{$0.22 \pm 0.48$} & $1.04(0.53,2.05)$ \\
\hline \multirow{2}{*}{\multicolumn{2}{|c|}{$\begin{array}{l}\text { Specific SLE within relationship stress subscale } \\
\text { in the past } 5 \mathrm{yr}\end{array}$}} & Whites, 10 & $\mathrm{SIL} / 68$ & hals & African Am & $\begin{array}{l}\text { icans, } 119 \mathrm{SIL} / 90 \\
\text { ormals }\end{array}$ \\
\hline & & $\begin{array}{l}\text { Prevalence of } \\
\text { stress, \% }\end{array}$ & $\mathrm{OR}^{\mathrm{a}}$ & $5 \% \mathrm{Cl}$ & $\begin{array}{l}\text { Prevalence of } \\
\text { stress, \% }\end{array}$ & $\mathrm{OR}^{\mathrm{a}}, \& 95 \% \mathrm{Cl}$ \\
\hline Divorce & & & & & & \\
\hline Event occurred (Yes/No) & & $25.9 \%$ ** & 2.71 & $6.23)$ & $9.3 \%$ & $2.48(0.73,8.44)$ \\
\hline Event occurred and very upset & & $11.2 \%$ ** & 4.66 & $17.62)$ & $3.8 \%$ & $4.11(0.63,26.96)$ \\
\hline Partner Infidelity & & & & & & \\
\hline Event occurred (Yes/No) & & $45.9 \%$ & 2.33 & $4.62)$ & $53.7 \%$ & $1.40(0.72,2.74)$ \\
\hline Event occurred and very upset & & $29.0 \%$ & 2.47 & $5.31)$ & $33.0 \%$ & $1.97(0.98,4.00)$ \\
\hline Increased number of arguments $\mathrm{n}$ & timate partner & & & & & \\
\hline Event occurred (Yes/No) & & $45.3 \%$ ** & 1.90 & $3.70)$ & $37.7 \%$ & $0.92(0.47,1.80)$ \\
\hline Event occurred and very upset & & $36.7 \%$ ** & 2.15 & $4.35)$ & $22.1 \%$ & $0.85(0.39,1.83)$ \\
\hline Severe physical abuse by an intim & artner (beaten up) & & & & & \\
\hline Event occurred (Yes/No) & & $20.6 \%$ ** & 5.45 & $14.80)$ & $14.4 \%$ & $0.47(0.17,1.36)$ \\
\hline Event occurred and very upset & & $19.6 \%$ ** & 5.28 & $14.45)$ & $11.5 \%$ & $0.51(0.18,1.49)$ \\
\hline Emotionally abused by intimate p & & & & & & \\
\hline Event occurred (Yes/No) & & $38.8 \%$ & 1.68 & $3.34)$ & $18.3 \%$ & $0.82(0.35,1.90)$ \\
\hline Event occurred and very upset & & $29.6 \%$ ** & 2.73 & $5.93)$ & $11.7 \%$ & $0.60(0.21,1.72)$ \\
\hline
\end{tabular}

${ }^{a}$ Subscale to include these events: death of close friend, family member or parent.

${ }^{\mathrm{b}}$ Subscale to include these events: divorce, infidelity of partner, increase in arguments with partner, beaten by partner, or psychologically abused by partner.

${ }^{\mathrm{c}}$ Subscale to include these events: moved back in with parents, woman or partner fired, woman arrested, woman homeless.

${ }^{\mathrm{d}}$ Subscale to include these events: woman robbed, beated by someone other than partner, forced to have sexual intercourse, partner arrested.

** $p$ value for test proportion or mean of SLE measure between race groups statistically significant.

events and count of high impact events), the four subscales of SLE. These analyses were stratified by race and adjusted for age, HR-HPV positivity, and lifetime number of male sex partners of the woman. For white women, the SLE count score $(p=.03)$ and the high impact SLE count scores $(p=.008)$ were associated with an increased risk of SIL, yet this association did not hold for African American women. For white women only, the relationship stress subscale alone was associated with SIL risk $(p=.002)$ and the association was stronger for high impact SLE count score $(p=.0005)$.

Of the five items making up the relationship stress sub- scale, the high impact measure (very upset) was associated with an increased risk of SIL for all five items; being divorced $(p=.03)$, partner infidelity $(p=.02)$, and being beaten by a partner $(p=.0008)$ were associated with SIL risk independent of how upset the woman was in response to the event. These associations were only statistically significant for white women. However, among African American women, being very upset by partner infidelity almost reached statistical significance $(p=.06)$.

Relationship stress was the subscale more strongly associated with SIL risk. A subanalysis indicated that the association 
between relationship SLE count score and SIL was stronger for high-grade than for low-grade cervical lesions (HSIL: aOR $=1.86,95 \% \mathrm{CI}=1.26,2.75 ; \mathrm{LSIL}$ aOR $=1.41 ; 95 \% \mathrm{CI}=$ $1.12,1.85)$ and the association was stronger for those reporting high impact relationship SLE items (HSIL: aOR $=2.14$, $95 \% \mathrm{CI}=1.41,3.27$; LSIL aOR $=1.56 ; 95 \% \mathrm{CI}=1.17$, 2.09 ), again, only for white women.

\section{DISCUSSION}

These findings are consistent with the limited comparable literature $(17,18,26,34)$. Our prior research linked childhood sexual abuse (27) and partner violence with cervical neoplasia (28). Psychological stress (18) and coping style (34) were linked to stress to increase risk of higher grade SIL and invasive cancer in small clinical studies. Other studies provide some evidence for the mechanism by which stress may affect cervical neoplasia risk through decreasing the woman's immunocompetence (17). One study (35) supports the finding that cervical neoplasia cases were more likely than controls to be diagnosed with alexithymia, and alexithymic women also had lower counts of a range of lymphocyte subsets. This suggests a role for psychological distress and immunosuppression in cervical neoplasia. Similarly, in a small $(N=60)$ case-case study, Lalos et al. (36) found that personality traits, specifically anxiety, substance dependence, and impulsivity were more common in cervical cancer cases relative to endometrial cancer, which is unlikely to have infectious etiology. Taken together this limited body of literature supports a potential role for psychosocial stress in cervical neoplasia development either directly or through suppression and its effects on risk of HR-HPV infection and persistence.

Although HR-HPV did not modify the association between SLE and SIL, HR-HPV was associated with the dichotomous higher SLE count score (Table 3). Furthermore, HR-HPV was significantly associated with the specific relationship stress item, being beaten by an intimate partner (OR adjusted for age, SIL case status, race $=3.26 ; 95 \% \mathrm{CI}=1.33,7.95$ ). These findings support a role for psychosocial stress in cervical neoplasia development through HR-HPV.

Our finding of a link between relationship stress and cervical neoplasia is supported, in part, by the earlier work of Kiecolt-Glaser and colleagues (37) who assessed problemsolving behaviors in couples and found that couples with more hostile behaviors when discussing marital problems were more likely than nonhostile couples to have a measurable immune function response. Kiecolt-Glaser and Newton (38) reviewed 64 articles and suggested that marital relationship functioning may have health consequences both indirectly through depression and health behaviors, and directly through the effect of the hostility on cardiovascular, endocrine, immune, and other physiological mechanisms.

We believe that our high-impact SLE count scores may be the superior measure relative to the SLE count score because this measure captures not only whether the negative effect occurred during the past 5 years but also whether the woman was very upset by the event. Some women may experience a negative event but be better able to cope with the negative event (captured here as not being upset). This distinction may be important biologically. Positive coping and increased social support have been linked to improved health outcomes among those experiencing severe stress $(15,39-44)$.

Differences in perceptions of stressors and ability to cope may be important in understanding the differences in SLE count scores report by race. We attempted to objectively measure whether a specific negative event had occurred and to then more subjectively assess the impact of the event on women. In this low-income population of white and African American women, we found that white women had significantly higher SLE count scores and higher high impact SLE scores than did African American women. To better understand racial differences in the response to SLE, we examined the impact of the SLE on woman by race. Among those reporting a stressful event, African American woman were significantly less likely than white women to be upset by the following: an increase in the number of arguments with a partner $(p=.001)$, being beaten up by a male partner $(p=$ $.009)$, and having to move back in with parents $(p=.001)$. African American and white women did not differ in their report of how upset they were in response to any of the 14 other stressful events assessed. We do not have measures of coping or social support (beyond relationship dissatisfaction) in these data. This information would be useful in assessing whether low-income African American women have a strong social support network or perhaps better coping skills than do low-income white women.

Several studies have noted race differences in stress levels and the impact of stress on health outcomes (46), including hypertension (8), preterm labor (47), mental health (48), and general health status (49-51). In a study comparing stress and social support among African American and white low-income pregnant women, African American women reported higher levels of chronic everyday stressors than white women, yet those stressors were more predictive of depression among white women (45). Baldwin et al. (52) found that African Americans reported more stress than whites and stress was associated with illness but African Americans were less likely to self-report illness. In a review and analysis of several studies assessing racial differences in health, Anderson et al. (53) argue that the mode of data collection may impact one's ability to detect racial differences in both stress and health outcomes methods. Self reports of illness conditions and symptoms show African Americans to be relatively well off compared with whites, whereas data collected from medical records or direct health examinations showed the inverse (53). This work may be particularly important in understanding our findings. African American and white women were asked to self-report stressful life events in face-to-face interviews. Perhaps, relative to white women, African American women were less willing to disclose events in face-to-face interviews with an interviewer who did not know the woman and was not of the same race or socioeconomic status as the woman. The result would then be an underestimation of stress levels in 
African American women and this could explain why we see no association between SLE scores and SIL among African American women.

This study has several limitations that deserve to be mentioned. We used the Hybrid Capture Tube system to detect high-risk HPV positivity, which has a sensitivity of $66.7 \%$ and a specificity of $98.6 \%$ to detect HPV relative to polymerase chain reaction methods (54). Since the inception of this study, the Hybrid Capture Tube has been replaced by the more sensitive and specific Hybrid Capture II system. Agreement between the Hybrid Capture Tube and Hybrid Capture II, adjusted for chance is good (Kappa statistic >0.65) (55). Furthermore, in our study, HR-HPV was significantly associated with SIL by grade and with the range of sexual risk factors for SIL, indicating that hybrid capture does provide a reliable indicator of HPV positivity for samples with a higher viral load. It is possible that sexual risk-taking behaviors on the part of the woman and her partner may explain association between SLEs and cervical neoplasia. However, we controlled for the etiologic agent, HR-HPV, and well as the lifetime number of sex partners of the woman.

Several study strengths also deserve mention. This is the largest epidemiologic study of psychosocial stress and cervical neoplasia and the first to adjust for HR-HPV. An important design feature of this study is that psychological stress questions were collected at baseline before the woman's knowledge of her ultimate disease status based on the cytology and pathology results collected at baseline and sent to the appropriate reference laboratory. Therefore, we increase the likelihood that psychological stress precedes and is not a consequence of knowledge of disease status. Given the longer latency period for preinvasive cervical neoplasia development ( $2-5$ years), those stressful events that could be etiologically linked to this disease development must occur with in a longer period (the past 5 years) than is typical for measurement of stressful life event.

Understanding the role of stress in cervical neoplasia development may explain why low-income women are at higher risk of this disease even when they have access to screening. Low-income women are not significantly more likely to be HR-HPV positive; yet low-income women are more likely to develop higher-grade cervical lesions and cancer (56-59). This may be a function of access to screening services or treatment for detected lesions (indirect mechanism), or it may be a function of the impact of stress, inadequate coping, or limited social support on disease development and progression (direct mechanism). Understanding the role of stress in cervical disease may also be helpful in designing prevention interventions that focus on stress reduction and foster effective coping strategies for women. These interventions would also have significant benefits for women in other aspects of health and well being.

This work was funded in part by National Cancer Institute Award R29-CA-57466 (to A.L. Coker), US Department of Defense Grant
N00014-96-1-1298, and by a Fullerton Foundation grant to the Medical University of South Carolina.

\section{REFERENCES}

1. Schiffman MH, Bauer HM, Hoover RN, Glass AG, Cadell DM, Rush BB, Scott DR, Sherman ME, Kurman RJ, Wacholder S. Epidemiologic evidence showing that human papillomavirus infection causes most cervical intraepithelial neoplasia J Natl Cancer Inst 1993;85:958-64.

2. Kjaer SK, van den Brule AJ, Bock JE, Poll PA, Engholm G, Sherman ME, Walboomers JM, Meijer CJ. Human papillomavirus-the most significant risk determinant of cervical intraepithelial neoplasia. Int J Cancer 1996;65:601-6.

3. Walboomers JM, Jacobs MV, Manos MM, Bosch FX, Kummer JA, Shah $\mathrm{KV}$, Snijders PJ, Peto J, Meijer CJ, Munoz N. Human papillomavirus is a necessary cause of invasive cervical cancer worldwide. J Pathol 1999; 189:12-19.

4. Hildesheim A, Schiffman MH, Tsukui T, Swanson CA, Lucci J 3rd, Scott DR, Glass AG, Rush BB, Lorincz AT, Corrigan A, Burk RD, Helgesen K, Houghten RA, Sherman ME, Kurman RJ, Berzofsky JA, Kramer TR. Immune activation in cervical neoplasia: cross-sectional association between plasma soluble interleukin 2 receptor levels and disease. Cancer Epidemiol Biomarkers Prev 1997;6:807-13.

5. Kadish AS, Ho GY, Burk RD, Wang Y, Romney SL, Ledwidge R, Angeletti RH. Lymphoproliferative responses to human papillomavirus (HPV) type 16 proteins E6 and E7: outcome of HPV infection and associated neoplasia. J Natl Cancer Inst 1997;89:1285-93.

6. Berkman L. Assessing the physical health effects of social networks and social support. Annu Rev Public Health 1985;5:413-432.

7. Cohen S. Psychosocial models of the role of social support in the etiology of physical disease. Health Psychol 1988;7:269-97.

8. Levenstein S, Smith MW, Kaplan GA. Psychosocial predictors of hypertension in men and women. Arch Intern Med 2001;161:1341-6.

9. Parkerson GR, Jr, Broadhead WE, Tse CK. Perceived family stress as a predictor of health-related outcomes. Arch Fam Med 1995;4:253-60.

10. Cohen S, Tyrrell DA, Smith AP. Psychological stress and susceptibility to the common cold. N Engl J Med 1991;325:606-12.

11. Cohen S, Doyle WJ, Skoner DP. Psychological stress, cytokine production, and severity of upper respiratory illness. Psychosom Med 1999;61: $175-80$.

12. Cohen S, Frank E, Doyle WJ, Skoner DP, Rabin BS, Gwaltney JM, Jr. Types of stressors that increase susceptibility to the common cold in healthy adults. Health Psychol 1998;17:214-23.

13. Cohen S, Tyrrell DA, Smith AP. Negative life events, perceived stress, negative affect, and susceptibility to the common cold. J Pers Soc Psychol 1993;64:131-40.

14. Cohen S, Doyle WJ, Skoner DP, Rabin BS, Gwaltney JM, Jr. Social ties and susceptibility to the common cold. JAMA 1997;277:1940-4.

15. Cohen S, Line S, Manuck SB, Rabin BS, Heise ER, Kaplan JR. Chronic social stress, social status, and susceptibility to upper respiratory infections in nonhuman primates. Psychosom Med 1997;59:213-21.

16. Goodkin K, Antoni MH, Helder L, Sevin B. Psychoneuroimmunological aspects of disease progression among women with human papillomavirus-associated cervical dysplasia and human immunodeficiency virus type 1 co-infection. Int J Psychiatr Med 1993;23:119-48.

17. Goodkin K, Antoni MH, Helder L, Sevin B. Psychosocial factors in the progression of cervical intraepithelial neoplasia-CIN [letter]. J Psychosom Res 1993;37:554-7.

18. Goodkin K, Antoni MH, Blaney PH. Stress and hopelessness in the promotion of cervical intraepithelial neoplasia to invasive squamous cell carcinoma of the cervix. J Psychosom Res 1986;30:67-76.

19. Antoni MH, Goodkin K. Host moderator variables in the promotion of cervical neoplasia-I. Personality facets. J Psychosom Res 1988;32: 327-38.

20. Byrnes DM, Antoni MH, Goodkin K, Efantis-Potter J, Asthana D, Simon T, Munajj J, Ironson G, Fletcher MA. Stressful events, pessimism, natural killer cell cytotoxicity, and cytotoxic/suppressor T cells in HIV + black women at risk for cervical cancer. Psychosom Med 1998;60:714-22.

21. Halpert R, Fruchter RG, Sedlis A, Butt K, Boyce JG, Sillman FH. Human papillomavirus and lower genital neoplasia in renal transplant patients. Obstet Gynecol 1986;68:251-8.

22. Frisch M, Biggar RJ, Goedert JJ. Human papillomavirus-associated cancers in patients with human immunodeficiency virus infection and ac- 
quired immunodeficiency syndrome. J Natl Cancer Inst 2000;92: $1500-10$.

23. Benton C SH, Hunter JAA. Human papillomavirus in the immunosuppressed. Papillomavirus Rep 1992;3:23-6.

24. Koutsky L. Epidemiology of genital human papillomavirus infection. Am J Med 1997;102:3-8.

25. Gentile G, Formelli G, Orsoni G, Rinaldi AM, Busacchi P. Immunosuppression and human genital papillomavirus infection. Eur J Gynaecol Oncol 1991;12:79-81.

26. DePunzio C, Salvestroni C, Guazzelli G, Papa MC, Freschi G, Ferdeghini M, Masoni S. Stress and cervical dysplasia. Eur J Gynaecol Oncol 1998;19:287-90.

27. Coker AL, Patel N, Krishnaswami S, Schmidt W, Richter DL. Childhood forced sex and cervical dysplasia among women prison inmates. Violence Against Women 1998;4:595-608.

28. Coker AL, Sanderson M, Fadden MK, Pirisi L. Intimate partner violence and cervical neoplasia. J Women's Health Gender-Based Med 2000;9: 1015-1023.

29. Norbeck JS. Modification of life event questionnaires for use with female respondents. Res Nurs Health 1984;7:61-71.

30. Norbeck JS. The Norbeck Social Support Questionnaire. Birth Defects Orig Artic Ser 1984;20:45-57.

31. Norbeck JS, Anderson NJ. Psychosocial predictors of pregnancy outcomes in low-income black, Hispanic, and white women. Nurs Res 1989;38:204-9.

32. Breslow NE, Day NE. Statistical methods in cancer research. Volume I: the analysis of case-control studies. Lyon, France: WHO International Agency for Research on Cancer, 1980.

33. SAS. SAS/STAT: changes and enhancements through release 6.12 (Guide). Cary, NC: SAS Institute, 1999. p. 1167.

34. Antoni MH, Goodkin K. Host moderator variables in the promotion of cervical neoplasia-II. Dimensions of life stress. J Psychosom Res 1989; 33:457-67.

35. Todarello O, Casamassima A, Daniele S, Marinaccio M, Fanciullo F, Valentino L, Tedesco N, Wiesel S, Simone G, Marinaccio L. Alexithymia, immunity and cervical intraepithelial neoplasia: replication. Psychother Psychosom 1997;66:208-13.

36. Lalos A, Eisenmann M, Lalos O. Personality differences between endometrial and cervical cancer patients in relation to sexual behavior. J Psychosom Obstetrics Gynaecol 1997;18:53-8.

37. Kiecolt-Glaser JK, Malarkey WB, Chee M, Newton T, Cacioppo JT, Mao HY, Glaser R. Negative behavior during marital conflict is associated with immunological down-regulation. Psychosom Med 1993;55: 395-409.

38. Kiecolt-Glaser JK, Newton TL. Marriage and health: his and hers. Psychol Bull 2001;127:472-503.

39. Coker AL, Smith PH, Thompson MP, McKeown RE, Bethea L, Davis K. Social support protects against the negative effects of partner violence on mental health. J Womens Health Gender Based Med 2002;11:465-76.

40. Kaslow NJ, Thompson MP, Meadows LA, Jacobs D, Chance S, Gibb B, Bornstein H, Hollins L, Rashid A, Phillips K. Factors that mediate and moderate the link between partner abuse and suicidal behavior in African American women. J Consult Clin Psychol 1998;66:533-40.

41. Blazer DG. Social support and mortality in an elderly community population. Am J Epidemiol 1982;115:684-94.

42. Chou KL, Chi I. Stressful life events and depressive symptoms: social support and sense of control as mediators or moderators? Int J Aging Hum Dev 2001;52:155-71.

43. Leserman J, Perkins DO, Evans DL. Coping with the threat of AIDS: the role of social support. Am J Psychiatry 1992;149:1514-20.

44. Thompson MS, Peebles-Wilkins W. The impact of formal, informal, and societal support networks on the psychological well-being of black adolescent mothers. Soc Work 1992;37:322-8.

45. Luchok K, Hall L, Westneat S, Mann N. Differences in the effects of workplace and non-workplace stress and support on depression during pregnancy by race and income. 14th Annual Women's Studies Conference. University of South Carolina, Columbia, SC, 2001.

46. Dimsdale JE. Stalked by the past: the influence of ethnicity on health Psychosom Med 2000;62:161-70.

47. MacKey MC, Williams CA, Tiller CM. Stress, pre-term labour and birth outcomes. J Adv Nurs 2000;32:666-74.

48. Ulbrich PM, Warheit GJ, Zimmerman RS. Race, socioeconomic status, and psychological distress: an examination of differential vulnerability. J Health Soc Behav 1989;30:131-46.

49. Schulz A, Israel B, Williams D, Parker E, Becker A, James S. Social inequalities, stressors and self reported health status among African American and white women in the Detroit metropolitan area. Soc Sci Med 2000;51:1639-53

50. Schulz A, Parker E, Israel DB, Fisher DT. Social context, stressors, and disparities in women's health. J Am Med Womens Assoc 2001;56:143-9.

51. Williams D, Lawler KA. Stress and illness in low-income women: the roles of hardiness, John Henryism, and race. Women Health 2001;32: 61-75.

52. Baldwin DR, Harris SM, Chambliss LN. Stress and illness in adolescence: issues of race and gender. Adolescence 1997;32:839-53.

53. Andersen RM, Mullner RM, Cornelius LJ. Black-white differences in health status: methods or substance? Milbank Q 1987;65:72-99.

54. Cope JU, Hildesheim A, Schiffman MH, Manos MM, Lorincz AT, Burk RD, Glass AG, Greer C, Buckland J, Helgesen K, Scott DR, Sherman ME, Kurman RJ, Liaw KL. Comparison of the hybrid capture tube test and PCR for detection of human papillomavirus DNA in cervical specimens. J Clin Microbiol 1997;35:2262-5.

55. Peyton CL, Schiffman M, Lorincz AT, Hunt WC, Mielzynska I, Bratti C, Eaton S, Hildesheim A, Morera LA, Rodriguiez AC, Herrero R, Sherman ME, Wheeler CM. Comparison of PCR- and hybrid capture-based human papillomavirus detection systems using multiple cervical specimen collection strategies. J Clin Microbiol 1998;36:3248-54.

56. Burk RD, Ho GY, Beardsley L, Lempa M, Peters M, Bierman R. Sexual behavior and partner characteristics are the predominant risk factors for genital human papillomavirus infection in young women. J Infect Dis 1996;174:679-89.

57. Munoz N, Kato I, Bosch FX, Eluf-Neto J, De Sanjose S, Ascunce N, Gili M, Izarzugaza I, Viladiu P, Tormo MJ, Moreo P, Gonzalez LC, Tafur L, Walboomers JM, Shah KV. Risk factors for HPV DNA detection in middle-aged women. Sex Transm Dis 1996;23:504-10.

58. de Sanjose S, Bosch FX, Munoz N, Tafur L, Gili M, Izarzugaza I, Izquierdo A, Navarro C, Vergara A, Munoz MT, Ascunce N, Shah KV. Socioeconomic differences in cervical cancer: two case-control studies in Colombia and Spain. Am J Public Health 1996;86:1532-8.

59. Villa LL, Franco EL. Epidemiologic correlates of cervical neoplasia and risk of human papillomavirus infection in asymptomatic women in Brazil. J Natl Cancer Inst 1989;81:332-40. 